\title{
SURGICAL TREATMENT OF REFRACTORY EPILEPSY ASSOCIATED WITH SPACE OCCUPYING LESIONS
}

\author{
EXPERIENCE AND REVIEW
}

\author{
PAULO THADEU BRAINER-LIMA, SWJAI RAO, ARTHUR CUKIERT, \\ ELZA MARCIA TARGAS YACUBIAN, GARY GRONICH, RAUL MARINO JR
}

\begin{abstract}
Surgery for space occupying lesions of the brain associated with intractable epilepsy represents a special problem because relief of the epilepsy is as much an operative goal as excision of the space occupying lesion itself. This study concerns 32 patients with space occupying lesions and intractable epilepsy who underwent excision of the lesion with acute intraoperative electrocorticography guided resection of the epileptogenic focus. Of the 32 patients, 16 formed a subgroup of gangliogliomas alone. The remaining were mixed lesions, predominantly benign. The duration of seizures in these patients ranged from 2 to 30 years, and the seizure frequency varied from 1 to 300 convulsions per month. The operative procedures included temporal corticectomy, amygdalo-hippocampectomy, and extratemporal corticectomies. Twenty nine patients were in Engel class I postoperatively, and three patients were in Engel class II. The findings with gangliogliomas are also considered in a separate group. This study strongly suggests that the operative procedure under electrocorticography guidance improves seizure outcome in space occuping lesions related intractable epilepsy.
\end{abstract}

KEY WORDS: brain tumor, ganglioglioma, refractory epilepsy, electrocorticography.

Tratamento cirúrgico da epilepsia refratária associada a lesões expansivas: experiência e revisão

RESUMO - O tratamento cirúrgico das lesões que ocupam espaço (LOE) do sistema nervoso associadas a epilepsia intratável representa um problema clínico especial, já que tanto o tratamento da lesão como o da epilepsia sảo relevantes. Estudaram-se 32 pacientes com LOEs que foram submetidos a lesionectomia com margens guiadas por eletrocorticografia. Destes, 16 possuíam gangliogliomas e os restantes lesōes variadas, predominantemente benignas. A duração das crises nesses pacientes variou de 2 a 30 anos e a frequência das crises de 1 a 300 por mês. Os procedimentos cirúrgicos incluíram corticectomia temporal, amigdalohipocampectomia e corticectomias extra-temorais. Vinte e nove pacientes estvam em grau I de Engel pósoperatoriamente e $3 \mathrm{em}$ grau II. Os achados em relação aos gangliogliomas foram também estudados separadamente. Este estudo sugere que a inclusāo da eletrocorticografia e da ressecçāo das margens epileptogênicas em pacientes com LOEs e epilepsia refratária melhoram os resultados obtidos em relação às crises.

PALAVRAS-CHAVE: tumor cerebral, ganglioglioma, epilepsia refratária, eletrocorticografia.

The surgical treatment of space occupying lesions (SOLs) of the brain associated with refractory epilepsy is an issue dogged by controversy. In such patients, surgery is directed as much towards the relief of seizures, as it is towards cure of the tumor. Many such patients are on supra-maximal doses of anticonvulsant therapy, freedom from which is another important goal. Many neurosurgeons believe that simple excision of the lesion alone is inadequate for this purpose'.

Departamento de Neurologia e Neurocirurgia, Hospital das Clínicas da Faculdade de Medicina da Universidade de São Paulo. Aceite: 12-abril-1996.

Dr. Arthur Cukiert - Rua Nova York 744 apto 131 - 04560-001 - São Paulo SP - Brasil. 
This study presents a series of 32 patients with SOLs and refractory epilepsy who underwent surgery to include the epileptogenic focus with the lesion, and examines on the basis of its results and of related literature the value of inclusion of the focus in the resection.

\section{PATIENTS AND METHODS}

One hundred and sixty patients were surgically treated at this center for epilepsy between 1992 and June 1995. This study includes 32 of these patients $(24.2 \%)$ selected retrospectively. Presence of SOLs associated with refractory epilepsy was the inclusion criterion. Refractory epilepsy was defined as persistent seizures (at least one per month) despite optimal or supra-optimal drug levels. Thirty two patients were included in this study with ages ranging from 6 to 57 years (mean 22.9). Twenty four of the patients were males (78\%), and 8 were females.

All patients were investigated by both computed tomography (CT), and magnetic resonance imaging (MRI). Surface inter-ictal multi-channel electroencephalography (EEG) and neuropsychological testing were carried out in all patients preoperatively. Two patients underwent the intra-carotid amytal procedure (IAP) preoperatively. All patients were under treatment by neurologists, and were receiving optimal or supraoptimal doses of multiple antiepileptic drugs.

All except one patient were operated under general anesthesia. Intraoperative electrocorticography (ECoG) was performed in 29 patients. The remaining 3 underwent stereotactically guided lesionectomy. The use of ECoG followed the protocol of first performing a base-line ECoG, followed by excision of the lesion. ECoG was then repeated to evaluate for residual spiking activity, which was then excised if feasible. Intraoperative mapping of the motor strip under general anesthesia was performed in 8 patients, and mapping of the Wernicke's area was carried out in the single patient who was operated under local anesthesia.

The operative procedures performed included temporal corticectomy with amygdalo-hippocampectomy (TCAH), temporal corticectomy (TC), extra-temporal corticectomy (ETC), posterior hippocampectomy (PH), and lesionectomy with stereotactic guidance (LS). Excision of the mass lesion, partial or total, was common to all, irrespective of additional or modified procedures for control of epilepsy. Total excision was confirmed by means of MRI.

All excised tissue was examined histopathologically; sixteen patients were diagnosed to have gangliogliomas (GG) and the other 16 patients had miscellaneous pathologies.

Post operative anti-epileptic treatment was continued for a period of one year with the same drug regimen as was being used before surgery. Where supra optimal doses were being used, they were reduced to optimal levels. Drugs were tapered off after one year under serial EEG control. All malignant lesions were irradiated post-operatively irrespective of the completeness of resection.

Patients were followed up with post-operative MRIs, neuropsychological testing and serial EEGs. Each of these was performed every 3 months, except MRI which was performed every 6 months in the presence of residual tumor. If no residual lesion was found, MRI was performed yearly.

\section{RESULTS}

The male predominance ( 24 male, 8 female) was statistically significant ( $p<0.03$ ). The earliest age of seizure onset was 1 year and the oldest was 48 years (mean 12.7 years). Patients with GG presented after a significantly longer duration of seizures than did patients with other lesions ( $p<0.03)$. Complex partial seizures were present in 29 patients $(90.6 \%)$, of whom $11(34.3 \%)$ had secondarily generalized convulsions. Three patients $(9.3 \%)$ had primarily generalized seizures.

In twenty four patients (75\%) EEG was unequivocally lateralised and 4 patients showed bitemporal interictal activity, 3 had diffuse spiking, and one had a normal recording. Table 1 show these findings correlated with the clinical and EEG findings.

No patient with GG had perilesional edema on the CT or MRI, and 5 patients had normal CT scans $^{34}$. Only 3 patients in this group had lesions with mass effect. Six patients had calcifications in 
Table 1. Outlines the clinical and EEG aspects of epilepsy in all patients. The correlation between the focus of seizures on EEG and the location of the corresponding lesions on MRI is also shown.

\begin{tabular}{|c|c|c|c|c|c|c|c|c|}
\hline Case & $\begin{array}{c}\text { Age } \\
\text { (years) }\end{array}$ & Sex & $\begin{array}{l}\text { Type of } \\
\text { seizures }\end{array}$ & $\begin{array}{l}\text { Age at } \\
\text { onset } \\
\text { (years) }\end{array}$ & $\begin{array}{c}\text { Duration } \\
\text { before } \\
\text { diagnosis }\end{array}$ & $\begin{array}{c}\text { Frequency of } \\
\text { attacks } \\
\text { (months) }\end{array}$ & $\begin{array}{l}\text { EEG } \\
\text { focus }\end{array}$ & $\begin{array}{l}\text { Tumor } \\
\text { location } \\
\text { on MRI }\end{array}$ \\
\hline 1 & 26 & $\mathbf{M}$ & PsiS/PcoS/Gen & 11 & 15 & 30 & left $T$ & left $T$ \\
\hline 2 & 11 & $\mathbf{M}$ & Gen & 4 & 7 & 8 & right $\mathrm{PO}$ & right $O$ \\
\hline 3 & 10 & $\mathbf{M}$ & PsiS/PcoS & 8 & 2 & 1 & left T & left T \\
\hline 4 & 10 & M & Pcos/Gen & 2 & 8 & 30 & right $T$ & right $T$ \\
\hline 5 & 19 & $\mathbf{M}$ & PsiS/PcoS & 9 & 10 & 80 & right $T$ & right Tin \\
\hline 6 & 26 & $\mathrm{~F}$ & PcoS/Gen & 18 & 8 & 16 & right $T$ & right $T$ \\
\hline 7 & 22 & $\mathbf{M}$ & PcoS/Gen & 3 & 19 & 1 & left $T$ & left $T$ \\
\hline 8 & 14 & $\mathbf{M}$ & PsiS/PcoS & 2 & 12 & 30 & right $\mathrm{O}$ & right $\mathrm{O}$ \\
\hline 9 & 57 & $\mathbf{M}$ & PcoS/Gen & 48 & 9 & 1 & left $T$ & left $T$ \\
\hline 10 & 16 & $\mathbf{M}$ & PsiS/PcoS/Gen & 4 & 12 & 2 & right $T$ & right $\mathbf{T}$ \\
\hline 11 & 36 & $\mathbf{M}$ & PcoS/Gen & 7 & 29 & 1 & right $F$ & right $F$ \\
\hline 12 & 25 & $F$ & PsiS/PcoS & 7 & 18 & 4 & bitemp & right $T$ \\
\hline 13 & 10 & $\mathbf{M}$ & $P \cos$ & 5 & 5 & 4 & diffuse & right $F$ \\
\hline 14 & 16 & $F$ & $P \operatorname{coS}$ & 7 & 9 & 12 & normal & left $P$ \\
\hline 15 & 32 & $\mathbf{M}$ & $\mathrm{PcoS}$ & 2 & 30 & 8 & bitemp & right $\mathbf{T}$ \\
\hline 16 & 15 & $\mathbf{M}$ & $\mathrm{PcoS}$ & 12 & 3 & 8 & right $T$ & right $\mathbf{T}$ \\
\hline 17 & 17 & $\mathbf{M}$ & PcoS/Gen & 14 & 3 & 90 & right $T$ & right $\mathbf{T}$ \\
\hline 18 & 16 & $F$ & PcoS/Gen & 12 & 4 & 300 & left $T$ & left $T$ \\
\hline 19 & 33 & $\mathbf{M}$ & Gen & 29 & 4 & 1 & right $T$ & right $\mathbf{T}$ \\
\hline 20 & 20 & $F$ & PcoS/Gen & 9 & 3 & 90 & right $F$ & right $F$ \\
\hline 21 & 49 & $F$ & PsiS/PcoS & 44 & 5 & 30 & right $T$ & right $T$ \\
\hline 22 & 24 & $\mathbf{M}$ & Gen & 21 & 3 & 1 & diffuse & left $O$ \\
\hline 23 & 28 & $\mathbf{M}$ & PsiS/PcoS & 44 & 5 & 30 & left $T$ & left $T$ \\
\hline 24 & 25 & $\mathrm{~F}$ & PcoS/Gen & 19 & 6 & 6 & left $T$ & left $T$ \\
\hline 25 & 26 & $\mathbf{M}$ & $P \cos$ & 6 & 20 & 120 & left $T$ & left $T$ \\
\hline 26 & 11 & $F$ & $P \operatorname{coS}$ & 2 & 9 & 300 & left $F \mathrm{~T}$ & left FT \\
\hline 27 & 12 & $\mathbf{M}$ & $P \cos$ & 9 & 3 & 30 & left $T$ & left F T \\
\hline 28 & 6 & $\mathbf{M}$ & SM area & 3 & 3 & 240 & diffuse & left $P$ \\
\hline 29 & 11 & $\mathbf{M}$ & PsiS/PcoS & 1 & 10 & 120 & left F T & left T \\
\hline 30 & 42 & $\mathbf{M}$ & PsiS/PcoS & 20 & 22 & 30 & right $T$ & right $\mathrm{F} T$ \\
\hline 31 & 34 & $\mathbf{M}$ & PcoS/Gen & 32 & 2 & 3 & left F & left $F$ \\
\hline 32 & 36 & $\mathbf{M}$ & $P \operatorname{coS}$ & 32 & 4 & 60 & right $\mathbf{T}$ & right $\mathbf{T}$ \\
\hline
\end{tabular}


Table 2. Correlation of the various lesions with their respective imaging characteristics, operative procedures, and outcomes.

\begin{tabular}{|c|c|c|c|c|c|c|c|c|}
\hline Case & Tumor site & Pathlogy & CT SCAN & MRI & $\begin{array}{c}\mathrm{ED} / \mathrm{MEF} \\
\mathrm{MEF}\end{array}$ & $\begin{array}{l}\text { Surgery extent } \\
\text { of excision }\end{array}$ & & $\begin{array}{l}\text { Outcome* } \\
\text { FU (month) }\end{array}$ \\
\hline 1 & left $T$ & GG & $\mathrm{HO}+$ & + & 0 & $\mathrm{TC}+\mathrm{AH}+\mathrm{L}$ & $\mathrm{T}$ & I (35) \\
\hline 2 & right $O$ & GG & HO - & + & MEF & $L+$ Marg & $\mathrm{T}$ & I (34) \\
\hline 3 & left $T$ & GG & normal & + & 0 & $\mathrm{TC}+\mathrm{AH}+\mathrm{L}$ & $T$ & I (33) \\
\hline 4 & right $T$ & GG & HO - & - & 0 & $\mathrm{TC}+\mathrm{AH}+\mathrm{L}$ & $\mathrm{T}$ & I (33) \\
\hline 5 & right $T$,In & GG & $\mathrm{HO}+$ & + & MEF & $\mathrm{TC}+\mathrm{AH}+\mathrm{L}$ & $\mathrm{Pe}$ & II (25) \\
\hline 6 & right $T$ & GG & HO - & - & 0 & $\mathrm{TC}+\mathrm{AH}+\mathrm{L}$ & $\mathrm{T}$ & I $(30)$ \\
\hline 7 & left $T$ & GG & normal & - & 0 & $\mathrm{TC}+\mathrm{AH}+\mathrm{L}$ & $\mathrm{T}$ & $I(26)$ \\
\hline 8 & right $O$ & GG & normal & + & 0 & $\mathrm{~L}+\mathrm{PH}+\mathrm{Marg}$ & $\mathbf{T}$ & I (26) \\
\hline 9 & left $T$ & GG & normal & - & 0 & $\mathrm{TC}+\mathrm{AH}+\mathrm{L}$ & $\mathbf{T}$ & I (4) \\
\hline 10 & right $T$ & GG & normal & + & 0 & $\mathrm{TC}+\mathrm{AH}+\mathrm{L}$ & $\mathbf{T}$ & $1(6)$ \\
\hline 11 & right $F$ & GG & $\mathrm{HO}-, \mathrm{CA}$ & - & 0 & L+Marg & $\mathbf{T}$ & I (30) \\
\hline 12 & right $T$ & GG & $\mathrm{HO}-$ & - & 0 & STEREO & $\mathbf{T}$ & I $(3 \mathrm{I})$ \\
\hline 13 & right $F$ & GG & $\mathrm{HO}+$ & + & 0 & L+Marg & $\mathbf{T}$ & I (4) \\
\hline 14 & left $P$ & GG & $\mathrm{HO}-$ & - & 0 & L+Marg & $\mathbf{T}$ & I (24) \\
\hline 15 & right $T$ & GG & $\mathrm{HO}-$ & - & 0 & STEREO & $\mathbf{T}$ & I (23) \\
\hline 16 & right $T$ & GG & $\mathrm{HO}+$ & + & MEF & $\mathrm{TC}+\mathrm{L}$ & $\mathrm{T}$ & $I(17)$ \\
\hline 17 & right $T$ & Astro.I & HO - & - & 0 & $\mathrm{TC}+\mathrm{AH}+\mathrm{L}$ & $\mathrm{T}$ & I (30) \\
\hline 18 & left $T$ & Astro.An & $\mathrm{HO}++, \mathrm{CA}$ & $+t$ & ED+MEF & $\mathrm{TC}+\mathrm{L}$ & $\mathbf{T}$ & $1(68)$ \\
\hline 19 & right $T$ & Oligo.An & $\mathrm{HO}++$ & ++ & ED+MEF & $\mathrm{TC}+\mathrm{L}$ & $\mathbf{T}$ & $1(18)$ \\
\hline 20 & right $F$ & Oligo. & $\mathrm{HO}++, \mathrm{CA}$ & ++ & $\mathrm{ED}+\mathrm{MEF}$ & L+Marg & $\mathbf{T}$ & I (25) \\
\hline 21 & right $T$ & Tuberc & $\mathrm{HO}++, \mathrm{CA}$ & ++ & 0 & $\mathrm{TC}+\mathrm{AH}+\mathrm{L}$ & $\mathbf{T}$ & $1(14)$ \\
\hline 22 & left $O$ & Astro.II & HO - & - & MEF & L+Marg & $\mathrm{Pe}$ & II $(50)$ \\
\hline 23 & left $T$ & Oligo. & $\mathrm{HO}-, \mathrm{CA}$ & - & 0 & $\mathrm{TC}+\mathrm{AH}+\mathrm{L}$ & $\mathbf{T}$ & I (24) \\
\hline 24 & left $T$ & Xnt.Astro & $\mathrm{HO}++$ & ++ & MEF & $\mathrm{TC}+\mathrm{AH}+\mathrm{L}$ & $\mathbf{T}$ & I (20) \\
\hline 25 & left $T$ & Astro.Piloc & HO - & - & 0 & $\mathrm{TC}+\mathrm{AH}+\mathrm{L}$ & $\mathbf{T}$ & $I(12)$ \\
\hline 26 & left $F$ & Astro.Fibr & $\mathrm{HO}$ - & - & MEF & L+Marg & $\mathrm{Pe}$ & I (28) \\
\hline 27 & left $F$ & Astro.Piloc & $\mathrm{HO}++$ & ++ & $\mathrm{ED}$ & $\mathrm{TC}+\mathrm{AH}+\mathrm{L}$ & $\mathrm{Pe}$ & I (26) \\
\hline 28 & left $P$ & Astro.Piloc & HO - & + & MEF & STEREO & $\mathrm{T}$ & I (26) \\
\hline 29 & left $T$ & Astro.II & HO - & + & 0 & $\mathrm{TC}+\mathrm{AH}+\mathrm{L}$ & $T$ & I (23) \\
\hline 30 & right $T$ & Oligo. & $\mathrm{HO}-$ & - & 0 & $\mathrm{TC}+\mathrm{AH}+\mathrm{L}$ & $\mathrm{Pe}$ & II (52) \\
\hline 31 & left $F$ & Oligo. & HO - & - & 0 & $\mathrm{TC}+\mathrm{AH}+\mathrm{L}$ & $\mathrm{T}$ & I (29) \\
\hline 32 & right $T$ & Astro.I & $\mathrm{HO}$ - & - & 0 & $\mathrm{TC}+\mathrm{AH}+\mathrm{L}$ & $\mathrm{T}$ & I (26) \\
\hline
\end{tabular}

AH, amygdalo hippocumpectomy; An, unaplastic; Astro, astrocytoma; CA, calcification; ED, edema; F, frontal; Fibr, fibrillary; GG, ganglioglioma; HO, hypodense; IN, insula; L, lesionectomy; Marg, margins; MEF, mus effect; O, occipital; Oligo, oligodendrogliona; P, parietul; Pe, partial excision; Piloc, pilocytic; Stereo, stereotactically guided lesionectomy; T, temporal; TC, temporal corticectomy; T, total excision; Tuberc, tuberculoma; $X \mathrm{nt}$, $\mathbf{x a n t h o a s t r o c y t o m a . ~}$

Plus or minus signs under CT indicate presence or absence of contrast induced enhancement. 
the lesions. The intensity of contrast enhancement of the lesions on both CT and MRI was greater in patients with miscellaneous pathologies, although no specificity could be discerned in other signal characteristics (Table 2).

All 29 patients who underwent ECoG were found to have spiking activity outside the immediate vicinity of the lesion. Three patients did not undergo ECoG, but had LS procedures because of lesions located in eloquent areas. Two patients underwent only temporal corticectomy without amygdalo-hippocampectomy, because the tumor was very posteriorly located. ETCs were performed on 5 patients in each group, each of whom had extratemporal lesions. The patient with the occipitotemporal lesion was found to have tumor growing into the posterior medial temporal lobe, and underwent PH also. Depth recordings showed no spiking from the head of the hippocampus. His seizure outcome corresponded to Engel class I. No patient with a temporal lesion was found to have an extratemporal seizure focus. Seven patients had partial resections because of involvement of sensitive areas by the tumors. Two post operative complications were seen. The patient with a lesion in the Wernicke's area who underwent surgery under local anesthesia with sparing of eloquent cortex suffered a temporary sensory dysphasia which improved within a week. One patient had a transient hemiparesis after frontal corticectomy, which recovered over 2 weeks.

The postoperative results in relation to seizures were assessed according to Engel's system . The average follow up was 26.3 months (4-68 months) there were 29 patients in class 1 and 3 in class II.

\section{DISCUSSION}

This study contains patients with a wide range of ages ( 6 to 57 years, mean 22.9). This wide variance agrees with other studies $s^{3-8}$ as does the predilection of GGs for younger patients ${ }^{29.31}$. One study insists that no age is more prone to $\mathrm{GGs}^{8.11 .29,37.53}$. There appears to be no bias towards either sex in most series ${ }^{25,29.48}$. Our series shows an overwhelming predominance of males, as does that of Castillo et al. ${ }^{\mathrm{x}}$.Traditionally, intractability of seizures has always raised suspicions of underlying structural lesions ${ }^{1.15,21.26 .28 .41}$. This review includes patients in whom additional corticectomy for control of intractable seizures was necessary, unlike in patients with tumors and non-refractory epilepsy in whom tumor excision is the sole concern.

The average duration of seizures prior to surgical treatment in our series was 9.3 years. KalyanRaman and Oliveiro ${ }^{31}$ noted that in their series of GGs the range of duration of seizures was from 5 to 16 years. Haddad et al. ${ }^{25}$ in their study of GGs found that the length of symptoms ranged from 3 months to 20 years (average 9.6 years). Reporting on intractable seizures associated with structural lesions, Awad et al.' found a mean duration of seizures of 9.6 years. Interestingly the longer duration of seizures in their work was associated with a non-contiguous, remote focus, which was explained partly by the supposition that the focus may not have represented true secondary epileptogenesis. Kirkpatrick et al. ${ }^{33}$ reported a mean seizure duration of 10.9 years for a series of low grade tumors (including 3 GGs). Thus, if malignant neoplasms are excluded, there appears to be some similarity between the various series on the duration of seizures. Also, there appears to be little difference between GGs, and non GG benign or low grade lesions in this regard. The three high grade lesions had seizure frequencies of 300,300 and 1 per month (mean 212.1), whereas for all the non-malignant lesions the mean was 37.4. This is an intriguing finding. Slow growing tumors have been argued to have a greater potential for provoking seizures ${ }^{39.41}$. This is presumably because slow growth allows time for "maturation" of the focus, a term that is often used in relation to various aspects of epilepsy. However, this epileptogenicity really denotes the incidence of seizures with each type of tumor, and not their severity. With a small non-randomized sample, it is difficult to determine whether these two profiles (short history of dense seizure clusters and long history of less frequent seizures) represent characteristic patterns of malignant and benign tumors respectively.

All the surgeries were performed by the same surgeon, ensuring some uniformity of technique. However, the term "lobectomy" is probably inappropriate here. The procedures performed here were really corticectomies guided by $\mathrm{ECoG}$, and not anatomical lobectomies. 
The patient follow-up here is varied. This has relevance to our results. It has been noted that the risk of recurrence of seizures remains for at least 2 years, but there is also evidence that freedom from seizures for one year probably ensures relief for at least the next five years.

The majority of patients in this study (87.5\%) had CPS, of which $39.2 \%$ secondarily generalized. Britton et al. ${ }^{3}$ have looked at 51 patients with partial epilepsy and tumors, and found that $92 \%$ of them had CPS. Other studies with heterogeneous tumor populations also show a predominance of CPS in their patients ${ }^{2.22 .50}$. In our series, 22 tumors $(68.7 \%)$ were located in the temporal lobes. Awad et al.' have 21 of 47 tumors causing intractable epilepsy so located. It must be noted here that as traditionally defined, CPS is not an anatomically localizing definition, and this may arise extratemporally ${ }^{5 l}$.

In this study, patients were split down the middle according to their tumor pathologies; $50 \%$ of them had GGs, the rest having miscellaneous lesions. Of the 16 GGs, 12 were temporal, 2 were frontal , 2 were occipital, and 1 was parietal. Haddad et al. ${ }^{25}$ found that 6 out of 13 GGs were temporal in location, a smaller percentage than ours, but they did note that the temporal lobe is the commonest site. Others have similar results ${ }^{\$-11.14 .29 .31 .47}$. This may or may not be related to the postnatal prolongation of neuronal growth and maturation of the temporal lobe. It is said GGs are seen in a minority of convulsive disorders ${ }^{24.25}$. This may be true as a percentage of all epilepsies, but seen as a function of CPS and refractory seizures the picture is less clear. Williamson et al. ${ }^{50}$ pointed out that between 5 and $10 \%$ of CPS will become refractory; however, how many such patients will have tumors is a moot issue. Kalyan-Raman and Olivero ${ }^{31}$ reported on 10 GGs ( $1.3 \%$ of all brain tumors) of which 6 were temporal. However, they did not mention what percentage they form of all tumors with seizures. Johannsson et al. ${ }^{\mathbf{x}}$ recorded that their cases represented $7.6 \%$ of pediatric intrinsic CNS tumors. Others provided figures varying from $0.4 \%$ to $1.7 \% \%^{20.24}$. None of these are seen as percentages of those tumor patients who had epilepsy, much less intractable CPS. Zentner et al..$^{53}$ in a study on temporal lobe epilepsy have shown that $40.5 \%$ of patients had GGs, but they have not mentioned their anatomical location.

It has been suggested that the combination of intractable CPS, young age, and hypodense cortical temporal lobe tumors may form a distinct complex ${ }^{16.38,54}$. It is tempting to consider that temporal GGs have a particular tendency to cause intractable epilepsy, specially CPS. This tendency is seen from the fact that lesionectomy alone relieved seizures in 9 of 14 patients with extra temporal lesions, but in only 2 out of 9 patients with temporal lesions $\mathbf{s}^{6}$. It is possible that secondary foci develop more often, and become autonomous more readily in the temporal lobes than in other areas of the brain ${ }^{16.42 .45}$. Whether GGs abet this process, or whether their association is merely a statistical illusion, needs to be looked into. The principle of amygdalo-hippocampectomy stems from the belief that in chronic temporal lesion related seizures the hippocampus suffers cell loss and becomes capable of independently sustaining seizures ${ }^{30,42}$. In almost $50 \%$ of patients who underwent ECoG and depth recordings in one series, spiking was seen from the medial temporal structures ${ }^{46}$. Whether this represents cause or effect is not known. In unresectable posteriorly located tumors, amygdalohippocampectomy has been beneficial ${ }^{16.30 .45}$. Indeed, even amygdalectomy alone, sparing the hippocampus has been useful in selected $\operatorname{cases}^{30}$.

The practical need of the neurosurgeon is to know how the seizure focus relates to the site of the lesion. Seizure foci may be coincident with the lesion, paralesional, but contiguous with it, or completely remote without a bridge of contiguity ${ }^{1.21 .27 .34 .35}$. Extracranial EEG (EEG-Ex) is inadequate for the purposes of surgical decision making. Some suggest that a third of refractory TLEs may have bitemporal EEG activity ${ }^{13.32}$. The chances of such findings increase with the duration of recording ${ }^{13.44}$. False localization of extratemporal seizures to the temporal area is also known ${ }^{13.40 .49}$. The importance of ECoG is in its expected ability to define the "cpileptogenic zone". In the series of Awad et al. ${ }^{1}, 36$ of 47 patients had seizure foci outside the lesion vicinity. Half of these were non-contiguously 
remote. For malignant lesions, the seizure focus was always remote and non contiguous. Jooma at al. ${ }^{30}$ have shown that excision of epileptogenic tissue that was identified by ECoG improved seizure control by almost 5 times compared to lesionectomy alone. Conversely, in two of their cases, intraoperative depth recording allowed them to spare excision of the hippocampus without compromise of the quality of seizure control.

The issue of ECoG is full of conflicting opinions as a result of mixed pathology samples, different methodologies used for monitoring and resection, and often very divergent opinions on basic definitions ${ }^{1.45 .12 .15 .21 .23,39.41 .43 .52}$. In this study, in all 29 patients in whom ECoG was used, abnormal area of spiking activity were identified, and excision of the epileptogenic zone was tailored to this area. Post excision ECoG showed deafferentation spikes with phase reversal in some patients, a finding which is not uncommon after such excisional procedures ${ }^{13}$. The previously seen spiking patterns were conspicuously absent. The results have vindicated the use of ECoG in these patients.

Depth recording is most useful in identifying hippocampal spiking activity, specially in simple partial seizures ${ }^{46}$. It has been argued that properly inserted subdural strips will have equal yields ${ }^{14,44,46}$, but given the propensity of these devices to provoke cerebral edema their use in the presence of SOLs must be cautiously considered. All 29 patients in this series who underwent TLAH had acute intraoperative depth recordings from the hippocampal head, and abnormal spiking was seen in all cases. The post operative seizure outcome appears to vindicate this. The single patient of PH had normal recordings, and the anterior hippocampus was spared to good effect ${ }^{30}$. Despite the fact that chronic temporal lobe lesions causing refractory epilepsy may be associated with a significant incidence of epileptogenic hippocampal changes ${ }^{30.42}$, it seems unreasonable to routinely excise this structure as a matter of policy. Depth recordings may help spare the innocent subject, and resect the deserving ones.

Extension of surgery to include epileptogenic areas has been questioned by many $y^{1,45.7 .17 .25 .31,39.43,47}$. However, there is a large volume of data to support $\mathrm{it}^{16,30,36,42}$. In our study, only three patients were in Engel Class-II post operatively, each of whom had only three seizure per year till the most recent review. Twenty nine patients $(90.6 \%)$ were seizure free (Engel Class-I) at the time of last follow up. In the study by Pilcher and Silbergeld ${ }^{39} 90 \%$ of patients with excision of focus and lesion were seizure free with one patient recording $90 \%$ improvement. This patient had an incomplete excision of focus. Wyllie et al.52 observed that seizure-tailored surgery showed better results than tumor directed surgery alone. It has been reported by Jooma et al. ${ }^{30}$ that $93 \%$ of those undergoing resection of the lesion with the epileptogenic zone were seizure free compared to only $19 \%$ of those undergoing lesionectomy alone. Reoperation to excise the seizure focus in those patients in whom excision of the lesion alone failed, resulted in a further $62.5 \%$ "complete seizure control". Cascino et al. ${ }^{6}$ have shown that $90 \%$ of temporal lobectomies, but only $50 \%$ of temporal lesionectomies became seizure free.

Sometimes, as in 7 of our patients, lesions may need to be incompletely excised because of invasion of eloquent tissue. In such patients, it has been recorded that excision of the seizure focus with partial resection of the lesion provides better control than partial lesionectomy alone ${ }^{l}$. Four patients out of $7(57.1 \%)$ in our study had partial lesionectomy with Engel Class-I results. Three had Engel class-II results. In all seven, surgery included the focus as defined by ECoG.

A comprehensive review of the issues associated with this is found in the work of Weber et al. 51 . They have compared 5 studies with patients who have undergone seizure surgery, or lesionectomy alone. The side-by-side placement of these results shows how difficult the task of comparison is. Discrepancies between different studies include lack of standardization of operative procedures, mixed lesion pathologies, variable follow-up parameters, and small sample sizes. Resorting to metaanalysis, they have shown that all these studies taken together, twice as many patients with only lesionectomy persist with seizures after 2 years as do those with seizure surgery. They also note that the presence of a larger fraction of refractory seizure patients in a sample may worsen the outcomes. 
Three groups of patients exist ${ }^{1,3 y}$. In one group, seizure foci are closely related to the lesion, and the focus is apparently unable to function independently after lesionectomy. Such patients should benefit from lesionectomy alone. In a second group, mature seizure foci are capable of autonomously provoking seizures, and would logically need excision. A third less distinct group is one where the focus is far removed from the lesion, capable of being autonomous and may be, on occasion, associated with another pathology such as mesial sclerosis ${ }^{39}$. The role of epileptogenic zone excision in these patients is, at best nebulous. Unfortunately, definite preoperative determination of which category a given patient belongs to is difficult at the present time. Reduced GABA and somatostatin in the perilesional "epileptogenic" tissue ${ }^{3 y}$ seen by immuno-histochemical techniques confirms the presence of an identifiable abnormality. The intention is to correlate this with persistent seizure activity, even after the lesion has been excised. On the other hand, this finding by itself does not indicate the need for resection.

In tumor related refractory epilepsy, control of the seizure disorder is as urgent and important a neurosurgical goal as the tumor "cure" itself. As in our study, patients with tumor related intractable seizures are often only mildly symptomatic for the tumors themselves, and are frequently on supraoptimal doses of antiepileptic medication. Taken together with the core of previously published related literature, our data strongly suggest that the resection of the focus under ECoG and depth recording guidance after appropriate preoperative EEG, imaging and neuropsychological assessment maximizes patient's chances of freedom from seizures, and from the harmful effects of aggressive long term drug therapy. This had led to excellent results in this study.

\section{REFERENCES}

1. Awad IA, Rosenfeld J, Ahl J, Hahn JF, Luders H. Intractable epilepsy and structural lesions of the brain: mapping, resection strategies, and seizure outcome. Epilepsia1991;32:179-186.

2. Boon PA, Williamson PD, Fried I, Spencer DD, Novelly RA, Spencer SS, Mattson RH. Intracranial intraixial SOLs in patients with intractable partial seizures: an anatomoclinical, neurophysiological, and surgical correlation. Epilepsia 1991;32:467-476.

3. Britton JW, Cascino GD, Sharbrough FW, Kelly PJ. Low grade glial neoplasms and intractable partial epilepsy; efficacy of surgical treatment. Epi lepsia 1994;35:1130-1135.

4. Cascino GD. Epilepsy and brain tumors: implications for treatment. Epilepsiat 1990;31:S37-S44.

5. Cascino GD, Kelly PJ, Hirschorn KA. Stereotactic resection of intraaxial cerebral lesions in partial epilepsy. Mayo Clin Proc 1990;65:1053-1060.

6. Cascino GD, Kelly PJ, Sharbrough FW. Long term follow up of stereotactic lesionectomy in partiul epilepsy: predictive factors and electroencephulographic results. Epilepsia 1992;33:639-644.

7. Cassaza M, Avanzini G, Broggi G. Epilepsy course in cerebral gangliogliomas: a study of 16 cases. Actu Neurochir 1989;46(Suppl):17-20.

8. Castillo M, Davis PC, Takei Y, Hoffman JC. Intracranial ganglioglioma: MR, CT and clinical findings in 18 patients. AJNR 1990;11:109-114.

9. Courville CB, Anderson FM. Neuro-gliogenic tumors of the central nervous system: report of two additional cases of ganglioglioma of the brain. Bull Los Angeles Neurol Soc 1941;6:154-176.

10. Demierre B, Stichnoth FA, Hori A, Spoerti O. Intracerebral ganglioglioma. J Neurosurg 1986;65:177-182.

11. Dorne HL, O'Gorman AM, Melanson D. Computed tomography of intracranial gangliogliomas. AJNR 1986;7:281-285.

12. Drake J, Hoffman HJ, Kobayashi J. Surgical management of children with temporal lobe epilepsy and SOLs. Neurosurgery 1987;21:792-797.

13. Engel J Jr. Approaches to localization of the epileptogenic lesion. In Engel J Jr (ed). Surgical treatment of the epilepsies. New York: Ruven Press, 1987:75-95.

14. Engel J Jr, Rausch R, Lieb JP, Kuhl DE, Crandall PH. Correlation of criteria used for localizing epileptic foci in patients considered for surgical therapy of epilepsy. Ann Neurol. 1981;9:215-224.

15. Falconer MA, Kennedy WA. Epilepsy due to small focal temporal lesions with bilateral independent spike discharging foci. J Neurol Neurosurg Psychiatry 1961;24:205-212.

16. Fish D, Andermnn F, Olivier A. Complex partial seizures and small posterior temporal or extratemporal structural lesions: surgical management. Neurology 1991;41:1781-1784.

17. Franceschuti S, Binelli S, Casazza M. Influence of surgery and antiepileptic drugs on seizures symptomatic of cerebral tumors. Acta Neurochir 1990;103:47-51.

18. Fried I, Kim, JH, Spencer DD. Limbic and neocortical gliomas associated with intractable seizures: a distinct clinicopathological group. Neurosurgery 1994;34:815-824

19. Garcia CA, McGarry PA, Colladia M. Ganglioglioma of the brainstem: case report. J Neurosurg 1984;60:431-434.

20. Garrido E, Becker LF, Hoffman HJ, Hendrick EB, Humphreys R. Gangliogliomis in children: a clinicopathological study. Child's Brain 1978;4.339-346. 
21. Goldring S, Gregorie EM. Surgical management using epidural recordings to localize the seizure focus: a review of 100 cases. J Neurosurgery 1973;60:457-466.

22. Goldring S, Rich KM, Picker S. Experience with gliomus in putients presenting with chronic seizure disorder. Clin Neurosurg 1986:33:15-42.

23. Gonzalez D, Elvidge AR. On the occurrence of epilepsy caused by astrocytoma of the cerebral hemisphere. J Neurosurg 1962;19:470-482.

24. Gueneiu G, Privat A, Drouet J, Court L. Subgranular zone of the dentate gyrus of young rabbits as a secondary matrix. a high resolution autoridiographic study. Dev Neurosci 1982;5:345-358.

25. Haddad SF, Moore SA, Menezes AH, VanGilder JC. Gangliogliomi: 13 yeirs of experience. Neurosurgery 1992;31:171-178.

26. Hoefer PFA, Schlesinger EB, Pennes HH. Seizures in patients with brain tumors. Assoc Res Nerv Ment Dis 1947;26:50-58.

27. Ives JR, Gloor P. A lo:ig term time lapse video system to document the patient's spontuneous clinicul seizure synchronized with the EEG. Electroencephalogr Clin Neurophysiol 1978;45:421-426.

28. Jabbari B, Huott AD, DiChiro G, Martin AN, Youngblood LA, Harper MG: Surgically correctable lesions solely detected by CT scan in adult onset chronic epilepsy. Ann Neurol 1980;7:344-347.

29. Johannsson GH, Rakete HL, Roessmann U. Gangliogliomas, pathological and clinical correlation. J Neurosurg 1981:54:58-63.

30. Jooma R, Yeh H, Privitera MD, Gartner M. Lesionectomy versus electrophysiological guided resection for temporal lobe tumors manifesting with complex pirtial seizures. J Neurosurg 1995;83:231-236.

31. Kalyan-Raman UP, Olivero WC. Ganglioglioma: a correlative clinicopathological and radiological study of 10 surgically treated cases with follow up. Neurosurgery 1987;20:428-433.

32. King DW, Ajmone-Marsan C. Clinical features and ictal patterns in epileptic patients with EEG temporal lobe foci. Ann Neurol 1977;2:138-147.

33. Kirkpatrick PJ, Honuvar M, Janota I, Polkey CE. Control of temporal lobe epilepsy following en bloc resection of low grade tumors. J Neurosurg 1993;78:19-25.

34. Mattson RH: Value of intensive monitoring. In Wada Ja, Penry JK (eds). Advances in epileptology: the $\mathrm{Xth}$ epilepsy international symposium. New York: Raven Press, 1980:43-51.

35. Moore JL, Cascino GD, Trennery MR. A comparative study of lesion resection with corticectomy with stereotactic lesionectorny in patients with temporal lobe lesional epilepsy. Epilepsia 1992; 33(Suppl 3):96.

36. Monis HH, Luders H, Hahn JF, Lesser RP, Dinner DS, Estes ML. Neurophysiological techniques as an aid to surgical treatment of primary brain tumors. Ann Neurol 1986; 19:559-567.

37. Naas R, Whelan MA. Gangliogliomas. Neuroradiology 1988;22:67-71.

38. Piepmeier JM, Fried I, Makuch R. Low grade astrocytomas may arise from different astrocyte lineage. Neurosurgery 1993;33:627-632.

39. Pilcher WH, Silbergeld DL. Intra operative electrocorticography during tumor resection: impact on seizure outcome in patients with gangliogliomas. J Neurosurg 1993;78:891-902.

40. Quesney LF, Gloor P. Localization of epileptic foci. Electroenceph Clin Neurophysiol 1985;37 (Suppl):165-200.

41. Rasmussen T. Surgery of epilepsy associated with brain tumors. In Purpura DP, Penry JK, Walter RD (eds). Neurosurgical managernent of the epilepsies. New York: Raven Press, 1975:227-229.

42. Spencer DD. Strategies for focal resection in medically intractable epilepsy. In Theodore WH (ed). Surgical treatment of epilepsy. Amsterdam: E]sevier, 1992,157-168.

43. Spencer DD, Spencer SS, Mattson RH. Intracerebral masses in patients with intractable partial epilepsy. Neurology 1984;34:432-436.

44. Spencer SS, Williamson PD, Spencer DD, Mattson RH. Combined subdural and depth electrode investigution in uncontrolled epilepsy. Neurology 1990;40:74-79.

45. Sperling MR, Cuhan LD, Brown WJ. Relief of seizures from a predominantly posterior temporal tumor with interior temporal lobectomy. Eplepsia 1989;30:559-563.

46. Sperling MR, $\mathrm{O}^{\prime}$ Connor MJ. Comparison of depth and subdural electrodes in recording temporal lobe seizures. Neurology 1989;39:1497-1504.

47. Sutton LN, Packer RJ, Rourke LB, Bruce DA, Schut L. Cerebral gangliogliomas during childhood. Neurosurgery 1983;13:124-128.

48. Tumpieri $D$, Moumdjian R, Melanson $D$, Ethier $R$. Intracerebral gangliogliomas in patients with partial complex seizures: $C T$ and MR imaging findings. AJNR 1991;12:749-755.

49. Theodore WH, Porter RJ, Penry JK. Complex partial seizures: clinical characteristics and differential diagnosis. Neurology 1983:33:1115-1121.

50. Williamson PD, Wieser HG, Delgado-Escueta AV. Clinical characteristics of partial seizures. In Engel J Jr (ed). Surgical treatment of the epilepsies. New York: Raven Press, 1994:49-63.

51. Weber JP, Silbergeld DL, Winn HR. Surgical resection of epileptogenic cortex associated with structural lesions. Neurosurg Clin N Am 1993;4:327-336.

52. Wyllie E, Luders H, Morris HH III. Clinical outcome after complete or partial cortical resection for intractable epilepsy. Neurology 1987:37:1634-1641.

53. Zentner J, Hufnugel A, Wolf HK, Ostertun B, Behrens E, Campos MG, Solymosi L, Elger CE, Wiestlar OD, Schramm J. Surgical treatment of temporal lobe epilepsy: clinical radiological and histopathological findings in 178 patients. J Neurol Neurosurg Psychiatry 1995;58:666-673.

54. Zimmerman RA, Bilaniuk LT. Computed tomography of intracerebral gangliogliomas. J Comput Tomogr 1979;3:24-30. 